\title{
ОЦЕНКА СТАРТАПА НА РАННЕЙ СТАДИИ ДЛЯ ФИНАНСИРОВАНИЯ И ИНВЕСТИЦИОННЫХ ЦЕЛЕЙ
}

\author{
(c) 2021 Вы Дык Ань \\ аспирант департамента менеджмента \\ Финансовый университет при Правительстве Российской Федерации, Россия, Москва \\ E-mail:voshka93@yandex.ru
}

Оценка стартапа на ранней стадии - это не только один из самых сложных, но и решающих аспектов финансирования стартапа. Это исследование направлено на определение методов оценки стартапов на ранних этапах во Вьетнаме, используемых на практике для целей финансирования и инвестирования стартапами и венчурными капиталистами, выявление и анализ несоответствий в оценке стартапов, которые влияют на их способность доступа к капиталу. Используя методы контент-анализа в качественном исследовании, было проанализировано 133 стартап-проекта во Вьетнаме, участвующих в реалити-шоу «Shark Tank» с целью привлечения капитала. Результаты исследований показывают, что существует множество методов оценки стартапов на ранних стадиях, в которых очень популярен метод мультипликатора. Кроме того, причиной неполучения доступа к капиталу проектами является то, что стартап использует неподходящие методы оценки, не основанные на доказательствах, практике и гибких корректировках.

Ключевые слова: Стартапы на ранней стадии, стартапы, венчурные капиталисты, методология оценки, Финансирование стартапов

\section{Введение.}

Во Вьетнаме продвижение стартапов является не только целью, но и средством реализации трех стратегических достижений, включая институты, инфраструктуру и человеческие ресурсы. Многие программы и политики поддержки стартапов были реализованы и продолжают развиваться (VCCI \& USAID, 2016). Вьетнам занимает 3-е место в Юго-Восточной Азии по количеству стартапов с быстрым ростом с 400 в 2012 году до 3000 в 2017 году (Phuong Anh, 2019).

Проблема, с которой сталкиваются стартапы - это найти правильный финансовый капитал для реализации своих идей и вывода продуктов на рынок. Потребность во внешнем финансовом капитале оценивается как весьма вероятная на ранних этапах стартапа (Abor, 2016). Хотя существует множество источников финансирования стартапов, но в основном можно их разделить на заемный и собственный капитал (Rogers, 2009). Однако из-за ограниченных финансовых результатов, неопределенности роста и асимметрии информации для стартапов на ранних стадиях трудно получить доступ к долговому финансированию. Вместо этого эти компании часто финансируются за счет собственного капитала, особенно от венчурных капиталистов с большими размерами капитала и высокой устойчивостью к риску.

По сравнению с листинговыми компаниями стартапам приходится искать, самим вести переговоры и привлекать капитал (Leach \& Melicher, 2011). Поиск потенциального капитала на рынке для стартапа на ранней стадии сопровождается переговорами о стоимости компании между предпринимателем и инвестором. Согласно Tyebjee \& Bruno (1984), оценка стартапов является наиболее важным вопросом в переговорах по привлечению капитала и представляет интерес как для инвесторов, так и для предпринимателей (Cumming \& Dai, 2011; Hsu, 2004; Gompers \& cộng sự, 2010). Поскольку стартапы заинтересованы в превращении возможностей в жизнеспособный бизнес и получении прибыли от своих инвестиций, они должны знать, как оценивать компанию, определять размер капитала. Инвесторы прежде, чем принять решение об инвестировании в компанию задаются вопросом сколько стоит эта компания? (Abor, 2016). Когда существует фундаментальная разница в оценке стартапа между предпринимателем и инвестором, это становится одной из основных причин неудачных переговоров по сбору средств и неспособности добиться инвестиций. Кроме того, стоимость компании зависит от метода оценки, и некоторые методы оценки могут быть лучше 
других (Schootbrugge \& Wong, 2013). Таким образом, использование соответствующих методов оценки очень важно для определения ценности основы переговоров, что увеличивает возможность привлечения инвесторов для стартапов.

Оценка стартапов - относительно новая тема, с которой связано множество исследовательских проблем. Из них будет очень полезно получить дополнительную информацию для начинающих владельцев стартапов во Вьетнаме и инвесторов о том, какие методы оценки целесообразно использовать на практике в целях финансирования средств, инвестирования и какие недостатки в оценке стоимости со стороны стартапов влияют на возможность получения финансирования. Однако до сих пор исследования методов оценки стартапов на ранних стадиях во Вьетнаме для целей финансирования и инвестиций все еще ограничены. Кроме того, хотя во всем мире существует множество эмпирических исследований практики использования методов оценки стартапов, результаты существенно различаются, и методы оценки используются по-разному в зависимости от институциональной среды стран (Lockett и другие, 2002; Manigart и другие, 2004). Таким образом, это исследование направлено на выявление методов оценки стартапов на ранних стадиях во Вьетнаме, используемых на практике стартапами и венчурными капиталистами для привлечения капитала и инвестиций. Выявление и анализ несоответствий в оценке стартапов, которые влияют на их способность получать доступ к капиталу.

\section{Методология исследования.}

Эмпирические данные были собраны с помощью первичных и вторичных источников. Это позволило соединить обоснованные теоретические результаты с практическими обобщениями. Собранные данные были проанализированы и сопоставлены с предыдущими исследованиями, а также послужили основой для ответа на вопросы исследования. В исследовании также был применен метод кейс-стади.

Результаты исследования.

Во многих исследованиях по всему миру изучались практические методы оценки стартапов на ранних стадиях. Oliveira \& Zotes (2018) исследовали и проанализировали различные методы, используемые для процесса оценки, и определили, какой метод лучше всего подходит для стартапов на бразильском рынке. Проведенные интервью с экспертами по оценке компа- ний, результаты исследования показывают, что наиболее часто используемые методы оценки по порядку включают методы дисконтированных денежных потоков, мультипликаторов, метод чистой стоимости, метод опционных моделей и, наконец, метод смешанных моделей.

Чтобы ответить на вопрос о том, как венчурные капиталисты оценивают свои инвестиции, Диттманн и другие (2004) использовали данные 53 немецких венчурных фондов, участвовавших на первом этапе на практике. Результаты показали, что в среднем 53 фонда-респондента использовали в среднем 2,92 метода оценки, и только 15\% из них использовали только один метод. Наиболее распространенными методами оценки являются методы дисконтирования денежных потоков и мультипликаторы. Кроме того, согласно Wright и Robbie (1998), проекты венчурного капитала часто оцениваются с использованием одного или нескольких методов оценки, включая оценку на основе мультипликаторов и методы дисконтирования денежных потоков. Между тем, модель дисконтированного денежного потока чаще всего используется венчурными капиталистами при оценке высокотехнологичных стартапов (Kilpeläinen, 2014).

В более широкой географической области исследования Manigart и др. (2000) изучили методы оценки, используемые венчурными капиталистами, участвовавшими не только на ранних стадиях инвестирования в Соединенных Штатах, но и в Великобритании, Франции, Бельгии и Нидерландах. Различия обнаруживаются, когда венчурные капиталисты придают разные приоритеты различным методам оценки, а теоретически правильные методы не всегда предпочтительны на практике.

Согласно Schootbrugge \& Wong (2013), одни методы оценки могут быть лучше других. Наличие надежного метода оценки важно для роста стартапов и венчурных капиталистов. В результате венчурные капиталисты часто применяют несколько методов оценки, а затем часто отдают предпочтение конкретному методу (Wright \& Robbie, 1996).

Согласно Aydın (2015), следует использовать подходящие методы оценки, основанные на характеристиках компании, в которой будет проводиться оценка, отрасли и страны, в которой компания работает. Чтобы дать более точную оценку, рекомендуется оценивать компанию, используя более одного метода, усредняя эти 
различные методы путем присвоения более высокого значения рассматриваемому методу. Использование нескольких методов оценки также значительно снижает процент неудачных инвестиционных сделок между венчурными капиталистами и стартапами (Dittmann и др., 2004).

Таким образом, теоретическая база и эмпирические исследования показывают, что методы оценки стартапов весьма разнообразны. В разных институциональных средах применяемый метод оценки стартапов также различается. Однако в конечном итоге исследования показали, что предпочтение отдается определенному методу оценки. Кроме того, выбор ненадлежащего метода оценки, не основанного на характеристиках компании и отраслевой практике, приведет к необоснованной оценке и неспособности привлечь капитал. Использование более чем одного метода оценки для определения диапазона стоимости стартапа может значительно снизить процент неудач при переговорах по сбору средств.

Для достижения целей исследования были использованы качественные методы исследования методами контент-анализа для раундов презентаций по сбору средств, переговоров и принятия инвестиционных решений по 133 проектам от компаний, работающих в различных сферах Вьетнама и принявших участие в программе Shark Tank.

После 3 лет реализации реалити-шоу «Shark Tank» было представлено 133 проекта, которые нуждались в привлечении капитала. Согласно статистическим результатам, 77 из 133 проектов увенчались успехом, 12 проектов отказались от получения инвестиций и 44 проекта не смогли привлечь капитал, в процентном соотношении проекты, которые не получили финансирование, составляет 42,11\% (Shark Tank, 2019 г.).

Подробное отслеживание и анализ процесса финансирования 133 проектов показали, что для стартапов и венчурных капиталистов имеется множество методов оценки, таких как метод мультипликаторов, метод, основанный на стоимости активов фирмы, метод венчурного капитала и метод дисконтирования денежных потоков. Среди них одним из широко распространенных методов оценки проектов этих стартапов является мультипликатор (мультипликатор выручки, мультипликатор валовой прибыли, мультипликатор чистой прибыли). Несколько других мультипликаторов, которые считаются отраслевыми, также используются для оценки стартапов. Характерным проектом стал проект по созданию социальной сети для туризма, который ожидает заполучить 200 тысяч пользователей в течение 3-6 месяцев. Учредитель оценивает доход от каждого пользователя этой сети примерно в 50 долларов США. Следуя оценке, которая опирается на доходы от этих пользователей, стоимость компании составит 10 миллионов долларов США.

Это показывает, что разные стартапы используют также разные методы оценки стоимости. Этот результат предоставляет подтверждающие доказательства для соответствующих теорий о методах оценки стартапов. Кроме того, результаты очень похожи на результаты некоторых исследований Oliveira \& Zotes (2018), Dittmann и другие (2004), Wright and Robbie (1998), Manigart и другие (2000). Распространенное использование метода мультипликаторов является подходящим методом для оценки стартапов на ранней стадии.

В сделках, в которых не удалось привлечь капитал, а также которые отказались от инвестиций от инвесторов, игнорируя другие факторы, предприниматель применял соответствующий своей отрасли и продукту метод мультипликаторов для оценки, но при этом слишком оптимистично оценивал «цифру» мультипликатора или же использовал несовместимые методы оценки, база оценки неоднозначна и основана на отраслевых практиках без гибкой адаптации к реальной ситуации компании.

В таких сделках можно упомянуть проект создания развлекательно-торгово-развлекательной зоны из контейнеров. Стартап предложил капитальные вложения в размере 10 миллиардов донгов за 10\% акций (что эквивалентно стоимости компании в 100 миллиардов донгов), в то время как текущая чистая прибыль составляет всего лишь около 3 миллиардов донгов. Согласно практике стоимость компании по сравнению с годовой чистой прибылью выше не более, чем в 5 раз, поэтому стоимость компании составляет всего 15 миллиардов донгов. Таким образом, хотя идея была хорошо изучена, помимо вопроса о стабильности рынка, нереалистичная оценка привела к тому, что проект не смог привлечь капитал от инвесторов.

Для проекта экспорта складных рам предприниматель хочет собрать 5 миллионов долларов в обмен на 10\% акций компании, что экви- 
валентно оценке компании в 1000 миллиардов донгов. Хотя выручка составляет всего несколько сотен миллионов в месяц, инвесторы указали на абсурдную точку оценки: чистая прибыль составляет около 6 миллиардов донгов в год, и согласно практике оценки компании с самой высокой ценой всего в 30 миллиардов донгов. Все инвесторы отказались и решили не вкладывать свои средства.

Проект компании по аренде комфортных офисов требует до 5 миллионов долларов США за $20 \%$ акций компании, что эквивалентно оценке компании в 25 миллионов долларов США или 500 миллиардов донгов с утверждением, что данная модель бизнеса единственная во Вьетнаме. Выручка компании составила 15 миллиардов донгов в 2016 году и 60 миллиардов донгов в 2017 году, а прибыль составила 4\% от выручки (600 миллионов донгов в 2016 году и 2,4 миллиарда донгов в 2017 году), но компанию сами оценивали в 500 миллиардов донгов (на 2018 год) с оценочным коэффициентом почти в 250 раз превышающим чистую прибыль. Помимо рискованности проекта, инвесторы посчитали стоимость компании завышенной и отказались вкладывать средства.

Точно так же был назван проект сетевого решения, объединяющего все рабочие места, чтобы помочь людям работать более эффективно. Стартап надеялся привлечь 100000 долларов (1\% капитала компании) от инвесторов, но в конце также не увенчался успехом. У этого проекта 1200 платящих клиентов, 500 постоянных платящих клиентов, учредитель оценил свою компанию в 10 миллионов долларов, расчет результатов был основан не на показателях прибыли, а на стереотипах сценариев технологической индустрии, таких как прогнозы на будущее и дисконтированные денежные потоки. Результаты сделки не оправдали ожиданий стартапа из-за опасений инвесторов по поводу проекта и слишком высокой стоимости компании.

Все эти результаты указывают на то, что при использовании ненадлежащего метода оценки, не основанного на отраслевых практиках с гибкой адаптацией к ситуациям компании, необоснованная и завышенная оценка может привести к трудностям поиска консенсуса между предпринимателем и венчурным капиталистом относительно общего знаменателя стоимости компании, и, следовательно, переговоры о капитале и инвестициях терпят неудачу. Это также согласуется с исследованиями Baeyens и другие (2006) и Aydin (2015).

\section{Предложения по политике.}

Результаты этого исследования предоставляют владельцам стартапов и инвесторов на ранних этапах дополнительные ресурсы, которые следует учитывать при ценообразовании в целях сбора средств и инвестирования.

Оценка может быть основана на различных методах, и для успешного привлечения капитала для поддержки роста стартап должен быть правильно оценен путем выбора правильного метода оценки. Среди них следует рассмотреть метод мультипликаторов, поскольку он совместим с финансовыми характеристиками стартапа на ранних этапах.

В дополнение к выбранному методу оценки оценка должна основываться на доказательствах, отраслевой практике, с гибкостью, позволяющей адаптироваться к ситуации в компании и избегать завышения оценки. Будет более разумно использовать более одного метода оценки для определения диапазона стоимости компании и в качестве основы для переговоров по сбору средств.

\section{Библиографический список}

1. Abor, J.Y. (2016). Entrepreneurial Finance for MSMEs: A Managerial Approach for Developing Markets. Switzerland: Palgrave Macmillan.

2. Baeyens, K., Vanacker, T., \& Manigart, S. (2006). Venture capitalists'selection process: The case of biotechnology proposals. International Journal of Technology Management, 34(1-2), 28-46.

3. Lockett, A., Wright, M., Sapienza, H., \& Pruthi, S. (2002). Venture capital investors, valuation and information: A comparative study of the US, Hong Kong, India and Singapore. Venture Capital, 4(3), 237-252.

4. Manigart, S., Wright, M., Lockett, A., Pruthi, S., Sapienza, H., Desbrières, P., \& Hommel, U. (2004). Venture capital investors, capital markets, valuation and information: US, Europe and Asia. Journal of International Entrepreneurship, 2(4), 305-326.

5. Aydin, N. (2015). A Review of Models for Valuing Young and Innovative Firms. International Journal of Liberal Arts and Social Science, 3(9), 1-8. 
6. Oliveira, F. B., \& Zotes, L. P. (2018). Valuation methodologies for business startups: A bibliographical study and survey. Brazilian Journal of Operations \& Production Management, 15(1), 96-111.

7. Phương Anh. (2019Вьетнам занимает 3-е место в Юго-Восточной Азии по количеству стартапов. Режим доступа: https://baodautu.vn/viet-nam-dang-dung-thu-3-o-dong-nam-a-ve-so-luong-doanh-nghiep-khoinghiep-d107823.html.

8. Shark Tank (2019). Режим доступа: https://sharktankvietnam.com/.

9. Tyebjee, T.T., \& Bruno, A.V. (1984). A model of venture capitalist investment activity. Management Science, 30(9), 1051-66. 